\title{
A THEORETICAL AND EMPIRICAL ANALYSIS OF THE STRATEGIC VALUE OF BEYOND COMPLIANCE occupational Health and Safety Programs
}

\author{
Daniel J. Corcoran \\ Joshua D. Shackman \\ Touro University International \\ Cypress, CA
}

\begin{abstract}
The present study examines the application of Resource Dependence Theory and Institutional Theory relative to company involvement in an important voluntary, governmentally sanctioned employee safety program that goes by the acronym VPP. Utilizing this combined theory approach, the study empirically demonstrates, through a design incorporating correlation and multiple regression analysis, that Institutional Theory is useful for predicting program prevalence within a given industry, though Resource Dependence Theory complements the former by offering an accounting of strategic firm behavion. Companies consider adoption of beyond compliance safety programs as a strategy to manage the expression of resource control power on the part of powerful stakeholders, while Institutional Theory helps to explain the mechanisms by which such programs proliferate through a given institutional field.
\end{abstract}

\section{Introduction}

The present study explores the efficacy of Resource Dependence Theory (RDT) and Institutional Theory (IT) as a theoretical foundation for understanding why organizations participate in beyond compliance safety and health programs. These two theories have frequently been used in concert in various attempts to explain organizational phenomena (Lucas, Avi-Itzhak, Robinson \& Morris, 2005; Peng, 2004) due, in part, to the shortcomings in each of the two perspectives that the other is capable of satisfying. Institutional theory, for instance, has been criticized in the past for focusing primarily on organizational adaptations resulting from institutional pressures including social values, norms and expectations imposed by the external environment without a great deal of consideration given to the influence of active agency and external exchange relationships that play a part in driving organizational change (Oliver, 1991; Pfeffer \& Salancik, 1978; Abernethy \& Fong, 1996). RDT, on the other hand, complements Institutional Theory in that active agency is essentially a fundamental tenet of the theory which also focuses specifically on exchange relationships with the external environment as they relate to resource inter- 
dependence between the firm and various stakeholder groups (Oliver, 1991; Pfeffer \& Salancik, 1978).

The present paper considers the marriage of these two theoretical perspectives as they relate to the emergence and growth of beyond compliance safety and health $(\mathrm{S} \& \mathrm{H})$ programs within institutional fields. The focal program evaluated in this study provides governmental recognition to employers for exemplary performance in their safety and health endeavors. This program, known as OSHA's Voluntary Protection Program (VPP) was created by the Occupational Safety and Health Administration (OSHA) in the early $80 \mathrm{~s}$ and requires that employers go well beyond what is minimally expected of them by OSHA standards (OSHA, n.d. (a)). Participants, for instance, are required to implement sophisticated health and safety management programs similar to those found in management systems prescribed to enhance product quality such as ISO quality standards, Six-Sigma, and Malcolm Baldridge Award criteria (Levine \& Dyjacka, 1997; Manuele, 2003). The intent behind VPP, therefore, is to provide recognition to employers that successfully protect their employees from workplace injuries and illnesses through the utilization of sophisticated management systems.

Thus, consideration for the employee stakeholder group weighs heavy in the decision to participate in VPP. However, participation also impacts the perception of the firm by other stakeholders having power to control resources important for firm survival. These include not only employees, but also the government, local community, customers, suppliers and other important stakeholder groups as well. Likewise, VPP has become a recognized, legitimate socially responsible endeavor and has proliferated within a number of industries. This proliferation in certain industries makes VPP a good candidate for evaluation from an institutional perspective. The combined explanatory efficacy of RDT and Institutional Theory will subsequently be utilized in the present paper to explore the phenomena of VPP proliferation within industries.

\section{Literature Review}

\section{Resource Dependence Theory}

Resource Dependence Theory grew out of the work of Pfeffer and Salancik and was first clearly explicated in their seminal book on the topic published in 1978 (recently republished in 2003). The theory is essentially based on the premise that resource interdependence relationships exist between organizations and their stakeholders. An imbalance in this relationship, where one actor is disproportionately more dependent on the other, creates a resource dependence power imbalance. Thus, a given resource dependence relationship can be one where the firm and stakeholder are highly dependent on each other, or one where circumstances create an imbalance resulting in one of the actors having resource control power over the other (Pfeffer \& Salancik, 1978).

In their book, Pfeffer and Salancik (1978) describe firm strategies for dealing with resource dependence ranging from mergers and acquisition to co-opting and 
lobbying powerful stakeholders. Since the publication of this book, a number of studies have been published attesting to the explanatory efficacy of RDT for understanding strategic decision-making in the firm. Jawahar and McLaughlin (2001), for instance, argue that companies choose from among several different strategies (ranging from proactive to reactive) for dealing with different stakeholders, depending on the organization's resource needs, which may fluctuate according to the developmental stage in the lifecycle of the firm. In another interesting paper, Jeff Frooman (1999) used RDT to propose a range of strategies that might be used by external stakeholders to control the resources of the firm depending on the degree to which a given firm is dependent on a given stakeholder group for resources necessary for survival. This perspective is consistent with the present paper in that we argue firms will themselves undertake strategy to influence relationships with stakeholders that could act to impinge upon the flow of resources through the firm.

\section{Institutional Theory}

Not unlike RDT, Institutional Theory views the firm as being influenced by, or more appropriately, embedded in an external environment. However, rather than focusing on power relationships, Institutionalism focuses on the existence of institutions external to the firm — such as laws, regulations, and norms - and the influence these institutions have on molding organizations in search of social legitimacy (Scott, 1995; Prakash, 2001).

DiMaggio and Powell (1983) further argued that organizations subjected to similar environments or 'fields' (such as firms within an industry), will respond to similar pressures in similar ways and may subsequently begin to resemble each other structurally or, in other words, become more homogenous or "isomorphic" in response. The authors termed this phenomenon 'institutional isomorphism' and proposed three primary mechanisms to explain why isomorphism occurs. These include coercive, mimetic, and normative mechanisms.

Coercive isomorphism "results from both formal and informal pressures exerted on organizations by other organizations upon which they are dependent and by cultural expectations in the society within which organizations function" (DiMaggio \& Powell, 1983). Mimetic isomorphic mechanisms include the tendency for companies to model other organizations when faced with an environment of ambiguity and uncertainty. Essentially, organizations will tend to model successful firms, or model strategies that are universally accepted by most firms in a particular sector. Normative isomorphism refers to professional influences on the firm resulting from professional training and education and influence from involvement with organizations such as professional associations outside the firm (DiMaggio \& Powell, 1983).

\section{RDT and Institutional Theory as Complementary Theories}

Christine Oliver (1991), in one of the earlier attempts at combining resource dependence theory with institutional theory, pointed to differences in the funda- 
mental underpinnings or foci of the two theories and described means by which the two theoretical perspectives could be combined to account for difficulties posed by a purely institutional viewpoint that arguably lacks means of accounting for active choice behaviors on the part of the firm. Thus, by incorporating a resource dependence perspective into the institutional framework, an accounting of strategic responses to the institutional environment can be made (Oliver, 1991).

\section{Empirical Studies}

Only a handful of empirical attempts have been made in the past decade demonstrating combined explanatory efficacy of the two theories in support of Oliver's framework. RDT and institutional theory, for instance, have been used to provide a theoretical basis for demonstrating strategic implications of incorporating accounting control systems as a part of overall management control systems. (Abernethy \& Fong, 1996). Other studies have been recently been published using RDT and IT as a theoretical basis for framing empirical research as well (Peng, 2004), including one such investigation which utilized the combined theory approach to establish a theoretical foundation for demonstrating the extent to which the external environment influences adoption of Total Quality Management initiatives in nursing homes (Lucas, Avi-itzhak, Robinson \& Morris, 2005). This latter study is instructive in that it provides an evaluation of the proliferation of a prescribed, beyond compliance management system within a highly regulated industry based on a combined RDT / institutional framework.

Not unlike the study performed by Lucas et al. (2005), the current paper uses the combined theory framework to ground an empirical evaluation of the emergence and proliferation of beyond compliance management programs in an otherwise regulated arena. And despite calls to consider this combined theoretical approach in evaluating strategy underlying the proliferation of environmental safety and health (ES\&H) programs as far back as 1997 out of "an urgent need for definition and theory building" (Tsai \& Child, 1997) a review of the literature suggests a combined theoretical approach has not been specifically employed in pursuit of this call. Nor have any attempts been made to examine specifically occupational safety and health (often regarded an ES\&H sub-discipline) programs from a strategic perspective regardless of theoretical approach. The present study will help to fill these deficiencies by: 1.) providing an empirical demonstration of the efficacy of the combined theory approach, an area sparsely populated with such demonstrations, 2.) providing a look into the extent to which this approach may help us to understand how beyond compliance programs such as VPP emerge and proliferate through institutional fields, and 3.) providing an in-depth evaluation of the perceived strategic value of occupational safety and health programs, an area largely unconsidered in the strategic management literature.

\section{VPP and the External Environment}

One aspect of the external environment that many organizations must cope with in the present age is that of activism and the media coverage that accompanies 
activism. According to Jeff Frooman (1999), activism may be employed as an indirect strategy on the part of some stakeholder groups that otherwise would have no power to impact the activities of the firm. Their power, therefore, is exercised indirectly, by influencing stakeholders - often by way of mass media - who provide resources necessary for the survival of the firm. Nor is activism necessarily restricted to the impact it may have on the firm, but entire industries as well (Shepard, Betz \& O'Connell, 1997; Milstein, Hart \& York, 2002; King, Lenox \& Barnett, 2002). Indeed, companies often find themselves in industries receiving a great deal of negative publicity and subsequently engage in strategies, such as participating in beyond compliance programs to demonstrate social responsibility; thereby setting themselves apart from their tarnished industry (Milstein et al., 2002). This may occur out of a concern that activism and negative public attention may cause more powerful stakeholder groups to respond by exercising control of resources they make available to the firm (e.g., customers choose to shop elsewhere) (Frooman, 1999). Companies in industries that receive a great deal of negative public attention are subsequently compelled to do something to set themselves apart by behaving responsibly, and one strategy for doing so is involvement with programs such as VPP. Through time, we would also expect an increase in VPP sites in a given industry due to mimetic and normative isomorphic mechanisms as described by DiMaggio and Powell (1983) as more companies in a given industry became aware of the program due to other VPP participants in the industry, and as managers' awareness of the program increased through educational opportunities. Thus, we hypothesize the following:

Hypothesis 1: VPP commitment in an industry is positively associated with the level of negative publicity in the industry.

\section{The Community as Stakeholder}

According to Besser (1999, p. 16), "The enlightened self-interest model of corporate social responsibility predicts that businesses that support their local communities will be more successful." Besser (1999) then goes on to demonstrate a link between community involvement in small towns and the perceived success of the businesses demonstrating that the community is instrumental in providing resources necessary to the success of the firm including a supply of workers, utilities, and legitimacy for continued operations.

Facilities that may be viewed as hazardous to a given community, therefore, will need to pay considerable heed to community concerns due to the inherent hazards associated with their operations. A large industrial facility that spews toxic pollutants into the atmosphere, for instance, may have difficulties winning over the community and this environmental threat will likely cause concern on the part of the firm resulting in strategy designed to appease the surrounding community. Thus, we subsequently suspect that the community will likely be seen as an important and powerful stakeholder in facilities such as these. These facilities will subsequently attempt to win over the community by enhancing firm 
legitimacy by not only focusing on environmental concerns, but also though the implementation of other socially responsible strategies as well. Hence:

Hypothesis 2:VPP commitment is positively associated with community environmental threats.

\section{Employees as Stakeholders}

Employees are an important primary stakeholder group that are likely to be seen as particularly powerful relative to the groups' power to control organizational resources. Larger companies in small communities will likely provide incentives to retain their existing force and entice employees from near-by communities in response to this power. And although some employers may hold what seems like monopoly power as the primary employer in a given community, failure to provide adequate incentives to maintain a limited labor force is not conducive to long term sustainability. Not all employees, for instance, are compelled to remain in a given community and when employees are scarce, companies are best not to provide incentives for emigration. Rather, incentives to inspire immigration would be more beneficial. VPP participation, thus, may be considered as among the set of strategic tools that may be employed to enhance the attractiveness of employment a given firm. This will be particularly so when dependence on labor is high. Thus, we hypothesize:

\section{Hypothesis 3a: VPP commitment is positively associated with community labor dependency.}

Another way to look at employee stakeholder power, of course, is to consider the proportion of unionized facilities within a given industry. One would expect, for instance that higher unionization within a company would tend to lead to strategies that would limit the exercise of resource control power on the part of the employee stakeholder group given their increased collective power. Companies within such an industry would, therefore, work to implement strategies to accommodate the organized labor group in order to prevent employees from withholding human resources either by strike or other means. Thus, another hypothesis for determining whether there is a relationship between employee stakeholder power and industry VPP commitment is as follows:

\section{Hypothesis 3b:VPP commitment is positively associated with the level of unionization.}

One could also argue that the level of technical competence may play a role in determining which industries become highly populated with VPP sites. That is to say, perhaps industries that require a technically skilled labor force tend to become VPP sites more often than low skill industries. It's plausible to assume, for instance, that employers who expend resources to train employees in a 
complex industrial skill will be more likely to tend to the concerns of employees in order to retain them (and the company's investment) than companies having front line employees where such an investment need not be made. Likewise, employees that acquire such skills should be duly compensated. Certainly one would expect a pharmaceutical chemical batch mixer to receive greater earnings than one who sweeps the workshop floor or plucks chickens at the company across the street. We subsequently used wage as a proxy for skill or technical competence.

Hypothesis 3c: VPP commitment is positively associated with employee wages.

\section{Injury Rate Prevalence}

To further test these relationships, it is important to consider whether companies having high injury rates account for increased VPP commitment within industries. This is important to determine whether injury rate has an effect and, if so, how significant an effect to discount the possibility of injury rate as an intervening or spurious variable. That is to say, companies in high-risk industries may choose to participate in VPP to lower their injury rates. If these industries also happen to be industries having large numbers of employees, or industries particularly scrutinized by OSHA or others due to their high rates, one could argue the existence of spuriousness, which would considerably water down the practical significance of the other relationships to be tested. Thus, to test the effects of this potentially intervening variable:

\section{Hypothesis 4: VPP commitment is positively associated with injury and} illness rates.

\section{The Government as Stakeholder}

Finally, in this study it is important that we consider the role of government. OSHA, for instance, is capable of a.) directly withholding company resources by imposing monetary penalties which have the potential of ranging into the tens of millions of dollars, b.) indirectly withholding resources by inciting other stakeholders to act due to OSHA's tendency to publicize large dollar penalties, and c.) controlling organizational resources through the promulgation of standards and administrative directives. OSHA frequently focuses on hazardous industries using a multi-pronged approach that includes tough but fair, focused enforcement, in addition to employing other strategies within the industry such as partnerships and alliances in an attempt to focus industries on significant safety and health issues inherent in their respective industries (Skrzycki, 2005). Thus, despite arguments suggesting a weak OSHA, the agency does wield considerable power in influencing the actions of employers brought into their field of vision. And given that OSHA tends to increase its inspection activities in industries exhibiting poor safety and health performance, the incidence of OSHA inspections within each 
given industry was selected as a construct for quantifying OSHA's focus within each industry. We subsequently hypothesize:

Hypothesis 5: VPP commitment is positively associated with the level of OSHA inspections.

\section{Methods}

A correlational, non-experimental design was used to test multiple hypotheses relating to relationships between stakeholder influence constructs and company VPP commitment. Methods of statistical analyses included correlation and multiple regression analysis using SPSS Grad pack, version 11.0.

\section{Sample Selection}

Data obtained from companies in this study included those possessing a VPP designation as of February 23, 2003 (the week the VPP data base was obtained). The data obtained from OSHA was arranged into two data sets for analysis. The first data set, made of companies at the 2-digit Standard Industrial Classification (SIC) level, was used to test the first hypothesis. This data set was comprised of all industries (2-digit SIC excluding construction and metal and mineral mining) that were eligible to participate in VPP. SIC codes were used as opposed to other classification schemes (e.g., NAICS) due to the way the information was reported by OSHA. Some industries were combined due to peculiarities in the SIC coding structure (Corcoran, 2003). A total of 60 industries remained for testing after these manipulations were completed. In this data set, the 2-digit SIC level was chosen due to constraints posed by the data sources. Thus, the first hypothesis was tested at the 2-digit SIC level.

Information was available at the 3-digit SIC to test to the remaining hypotheses and thus, the second data set made use of this more specific information for the remaining comparisons. This data set was comprised of all manufacturing industries having VPP sites at the 3-digit SIC level, plus two utility industries (SICs 491 and 493 ) due to limits imposed by one of the primary independent variables (Corcoran, 2003). Thus, all manufacturing and relevant utility and warehousing industries (3-digit SIC) having VPP sites were included in the data set except that two primary metal industries were excluded as outliers (Corcoran, 2003). This resulted in an industry population of 903 -digit SIC industries.

VPP commitment was measured by looking at each industry at the 2-digit and 3-digit sic level, depending on the comparison being made. VPP commitment within each industry was determined at the firm and establishment level. At the firm level, the number of multiple facility VPP firms in each industry was divided by the number of all firms (derived from census data, U.S. Census Bureau, n.d. (a)) in each respective industry. At the establishment level, the total number of VPP sites within each industry, was divided by the number of all establishments in each respective industry. A value of 0.1 was added to the numerator as a place- 
holder for those industries having no sites or zero values. Histograms, means and standard deviations for these two variables at both the 2 and 3-digit SIC level are depicted are depicted in Figure 1. Current data for VPP industry prevalence are available on OSHA's web site (OSHA n.d. (b)) at the 2, 3 and 4-digit level.

\section{Figure 1}

\section{Histograms and Descriptive Statistics for Dependent Variables}

2 Digit SIC Dependent Variables
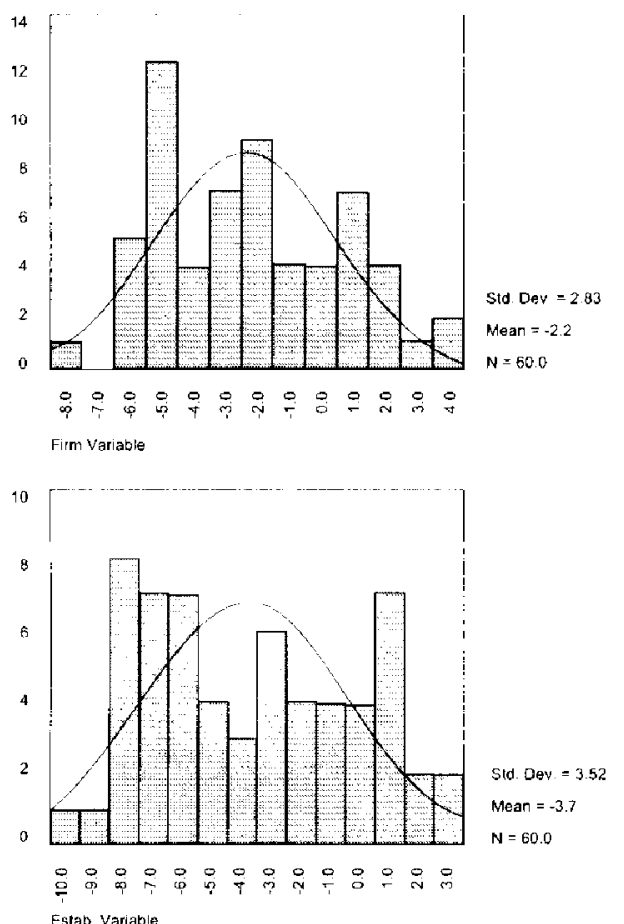

3 Digit SIC Dependent Variables
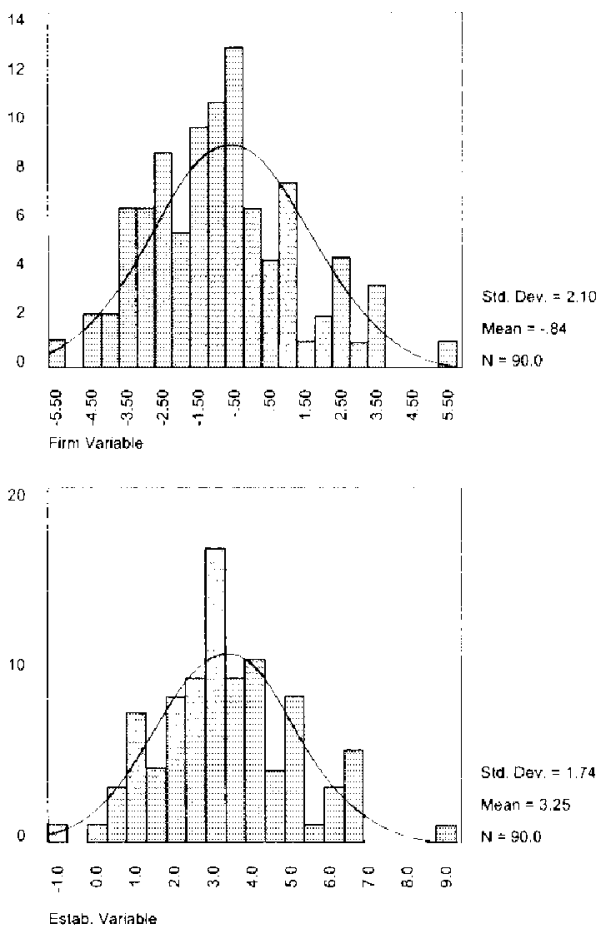

Figure 1 depicts histograms, means, and standard deviation for Firm and Establishment dependent variables for both the 2 and 3 digit SIC comparisons.

\section{Negative Public Attention Constructs}

Negative Public Attention [From Hypothesis 1]: This variable construct was measured based on the amount of bad press a given industry sustained. To operationalize this construct, the number of negative press news articles for each industry were analyzed to identify the relative number published over a threeyear span of time, from 2000 through 2002 . These values were tabulated for each industry, then divided by the number of firms and number of establishments in each respective industry, using 0.1 as a numerator place-holder for zero values. Articles were randomly selected from two sources, first using a Boolean key word search of the UMI, Proquest data-base which utilized an ES\&H related key word search string. Second, articles were selected from among those collected by www.corpwatch.com. This advocacy group has a research staff that collects 
negative press from various newspapers around the world on a daily basis. In both cases, all bad press articles were included in their respective tallies. In the latter case, a number of articles tied to bad press were included resulting from organizational misconduct unrelated to environmental safety and health. Thus, use of these two article sources included constructs that both included and excluded bad press unrelated to ES\&H.

Articles were tallied for each industry group at the 2-digit SIC code level excluding construction. The 2-digit SIC level was chosen due to the nature of newspapers to focus on larger industry sectors (e.g., the 'Oil Industry') as the focus of their articles and the articles could not subsequently be coded at a more specific level (e.g., 3-digit SIC level).

Community Environmental Threat [From Hypothesis 2]: One way in which a facility may pose a threat to a given community can be measured in the amount of toxic substances they release into the environment. The worst, single polluter in each 3-digit SIC was identified from among the top 100 polluting companies in each 2-digit SIC from the EPA's Toxic Release Inventory web page (U.S. EPA, n.d.). Their total toxic emissions into the environment were recorded as representative of their industry. Three, 3-digit industries did not rank in the top 100 of their 2-digit SIC. A value equal to the order of magnitude of the 100th ranked polluter in their respective 2-digit industries was assigned to these industries (Corcoran, 2003).

Labor dependency / Scarcity [From Hypothesis 3a]: This was the first of three constructs for gauging relative resource control power of the employee stakeholder group. This variable was measured by determining the number of those employed at each VPP site per county population, and then averaging the resulting values for each industry. Employee populations were derived from OSHA's internal VPP data-base. County populations were determined from 2001 Census estimates (US Census Bureau, (n.d. (b)). This variable subsequently reflects the average labor availability for VPP sites in each respective industry.

Unionization [From Hypothesis 3b]: Unionization included the proportion of unionized VPP sites in each 3-digit SIC industry. Unionization was chosen as a variable for measuring the degree of employee resource dependence power in that labor unions provide the employee stakeholder group with collective power the group would not otherwise have.

Wage [From Hypothesis 3c]: Wage was determined by dividing the total payroll in each industry by the number of employees in each industry from data obtained from the US Census Bureau (n.d. (a)). Nineteen ninety seven data was used since this appears to be the last year that the SIC classification system was used.

Injury and Illness Rates, [From Hypothesis 4]: The total injury and illness rate for each of the industries having VPP companies were obtained from the Bureau of Labor Statistics (BLS) from 2001 (BLS, 2002) at the 3-digit SIC code level. This incidence rate is determined by the number of injuries and illnesses, multiplied by 200,000 , divided by the total number of hours worked in the year. 
These rates reflect industry averages and typically serve as a benchmark average for a given industry. These rates also provide an indication of the relative magnitude of the hazards inherent in the work performed in a given industry as compared to other industries.

OSHAAttention to Industry [From Hypothesis 5]: This comparison included the number of inspections conducted by OSHA over one year ranging from March of 2002 to March of 2003. This information was taken from OSHA's inspection statistics web page at the 3-digit SIC level and was obtained by entering the appropriate SIC code on the site. Only data from the year previous to the date of entry can be obtained through this internet interface (OSHA, n.d. (c)).

\section{Analysis}

The data for the majority of the variables collected for this investigation were not distributed normally. This was particularly true of the dependent variables. All variables except for the variable measuring industry injury rate (coded INJURAT in this analysis) were subsequently log normalized yielding approximately normal distributions. Pearson's correlation and multiple regression analyses were conducted to test the hypotheses.

\section{Results}

\section{Introduction}

Table 1 depicts the results from correlation analyses for the 2-digit SIC comparisons. Recall from Hypothesis 1 that the independent variable constructs included the "Negative Public Attention" constructs for both the advocacy group and Proquest articles. These variables were coded as ADVOC and PROQU respectively. The dependent variables included Firm Level and Establishment level VPP commitment variables at the 2-digit SIC, and were coded FIRM and ESTAB respectively.

These coefficients indicate moderately strong to strong correlations for all possible comparisons between the independent variables and both dependent variables thereby confirming the relationship proposed in Hypothesis 1 .

\section{3-Digit SIC Comparisons}

Results from the simple correlation analysis for the 3-digit SIC comparisons are depicted in Table 2.

Note from Table 2 that all major 3-digit SIC hypotheses were confirmed through Pearson correlation analyses except for Hypothesis 4 which predicted a positive relationship between VPP prevalence and injury rate. Injury rate, however, was not positively correlated with either dependent variable as anticipated. In fact, a moderate inverse relationship was noted, which will be discussed further in relation to regression results. The construct for measuring community environmental threat (coded as ENVIR), however, indicated a weak to moderate correlation with both dependent variable constructs. Likewise, the Employee constructs including 
Labor Dependency, Union Prevalence and Wage (coded LABOR, UNIO, and WAGE) resulted in weak to moderate significant correlations.

Table 1

Pearson's Correlation Coefficient Matrix for 2 Digit SIC Comparisons

\begin{tabular}{llcccc}
\hline & & FIRM & ESTAB & ADVOC & PROQU \\
\hline \multirow{2}{*}{ FIRM } & Pearson Correlation & 1 & $.952^{* *}$ & $.800^{* *}$ & $.816^{* *}$ \\
& Sig. (2-tailed) &. & .000 & .000 & .000 \\
\multirow{2}{*}{ ESTAB } & Pearson Correlation & & 1 & $.694^{* *}$ & $.721^{* *}$ \\
& Sig. (2-tailed) &. & .000 & .000 \\
\multirow{2}{*}{ ADVOC } & Pearson Correlation & & 1 & $.864^{* *}$ \\
& Sig. (2-tailed) & & & .000 \\
\multirow{2}{*}{ PROQU } & Pearson Correlation & & & & 1 \\
& Sig. (2-tailed) & & & &. \\
\hline
\end{tabular}

* $p<.05$

** $\quad p<.01$

Note: $\mathrm{N}=60$

Table 2

Pearson's Correlation Coefficients for 2 Digit SIC Comparisons for FIRM and ESTAB dependent variables for 3 digit SIC comparisons

\begin{tabular}{llcccccc}
\hline & & ENVIR LABOR & OSHA INJURAT UNIO & WAGE \\
\hline \multirow{2}{*}{ FIRM } & Pearson & & & & & & \\
& Correlation & $.432^{* *}$ & $.281^{* *}$ & $.292^{* *}$ & $-.474^{* *}$ & $.434^{* *}$ & $.288^{* *}$ \\
& Sig. (2-tailed) & .000 & .007 & .005 & .000 & .000 & .006 \\
\hline \multirow{2}{*}{ ESTAB } & Pearson & & & & & & \\
& Correlation & $.394^{* *}$ & $.277^{* *}$ & $.349^{* *}$ & $-.422^{* *}$ & $.408^{* *}$ & $.247^{*}$ \\
& Sig. (2-tailed) & .000 & .008 & .001 & .000 & .000 & .019 \\
\hline
\end{tabular}

\footnotetext{
* $\quad \mathrm{p}<.05$

** $\quad p<.01$

Note: $\mathrm{N}=90$
} 


\section{Regression Analysis Introduction}

Multiple regression analyses were conducted with the variables presented in Hypotheses 2 through 5 above. Analysis of residuals, tolerances, and tests for linearity between independent and dependent variables indicated that regression assumptions were generally met and multicollinearity was ruled out. The only exception to the regression assumptions was that the UNIO variable did not have an approximately normal distribution, though analysis of residuals for equations including this variable did not appear to be affected.

Various combinations of the Community, Employee and Government stakeholder variables were regressed against the firm level dependent variable as depicted in Table 3. Note that the introduction of the ENVIR variable obscured the contribution of the LABOR and OSHA variables (Columns / Equations $1 \& 2$ ). This may be due to shared variation related to employer size as large facilities are more likely to emit large quantities of chemicals, have need for more employees, and are more likely to get the attention of OSHA. Likewise, although not included in this presentation of the results, the addition of the ENVIR variable completely obliterated any contribution made by the WAGE variable discussed in the previous section. This latter variable was subsequently omitted from the presentation of results.

Table 3

Standardized Coefficients for Various Multiple Regression Equations for the Firm Level Dependent Variable FIRM

\begin{tabular}{lcccccc}
\hline Firm Level & $\mathbf{1}$ & $\mathbf{2}$ & $\mathbf{3}$ & $\mathbf{4}$ & $\mathbf{5}$ & $\mathbf{6}$ \\
\hline LABOR & $.261^{*}$ & .185 & $.261^{* *}$ & & & \\
OSHA & $.273^{* *}$ & .166 & $.355^{* * *}$ & $.325^{* * *}$ & .158 & $.239^{*}$ \\
ENVIR & & $.329^{* * *}$ & $.241^{* *}$ & $.238^{* *}$ & $.269^{* *}$ & \\
INJURAT & & & $-.599^{* * *}$ & $-.527^{* * *}$ & & \\
UNIO & & & & $.235^{* *}$ & $.323^{* *}$ & $.403^{* * *}$ \\
\hline R $^{2}$ & .153 & .243 & .565 & .550 & .303 & .245 \\
ADJ. R $^{2}$ & .133 & .216 & .544 & .529 & .278 & .227 \\
\hline
\end{tabular}

$$
\begin{array}{rl}
* & \mathrm{p}<.05 \\
* * & \mathrm{p}<.01 \\
* * * & \mathrm{p}<.001 \text { (2-tailed) }
\end{array}
$$

Table 3 depicts standardized coefficients for 6 multiple regression equations. The variables included in each equation are determined by the vertical columns. All regression equations were significant at $p<.001 . R^{2}$ values are also provided. 
Of particular interest in examining the equations presented in Table 3, however, is what happens in the third equation when the INJURAT variable was added to the mix of variables considered in Equation 2. This variable appears to exhibit a unique range of variation considerably increasing the $\mathrm{R}^{2}$ value of the equation from .243 in equation 2 to .565 in Equation 3. The standardized coefficients of the stakeholder variables are enhanced as well in the latter equation and the standardized coefficient for the INJURAT variable (-.599) suggests an important contribution for this variable. Utilizing other arrangements of the stakeholder variables confirm the importance of the INJURAT variable is important for explaining the variation in the dependent variable as evidenced by a marked increase in $\mathrm{R}^{2}$ values when the INJURAT variable is added. Note the comparison, for instance, between Equations 4 and 5 . In this latter equation the UNIO construct was used in lieu of the LABOR construct as the employee stakeholder variable. In essence, therefore, the various equations considered in this post hoc analysis suggest that there is combined explanatory efficacy in using the employee, community, and governmental stakeholder constructs developed in this study. In addition, the inclusion of the INJURAT variable considerably enhances the usefulness of these regression equations in predicting VPP industry prevalence.

\section{Establishment Level Equations}

Note that the relationships between the various arrangements of independent variables included in Table 4, when regressed against the ESTAB dependent variable, are essentially similar to those described in Table 3 . That is to say, changes in coefficients and significance follow very similar trends between tables. Thus, we will limit our discussion to differences between the findings described by the two tables.

One of the first marked differences between tables can be noted in Equation 2. In Table 3, only the ENVIR variable standardized coefficient is significant. In Table 4, however, all three variables are significant. However, the contribution to the regression in Table 3 of LABOR and OSHA were not far from a significance level of .05 , and would certainly have been significant at 0.1 . Indeed, this seems to be the case for all variables that did not appear significant in Table 3, but appeared as significant at $\mathrm{p}<.05$ in Table 4 .

Perhaps what is of more interest then is the greater level of significance in the ENVIR variable in Table 3 as compared to Table 4. Indeed, this difference in significance is apparent in all regression equations that include this variable. However, it does seem to make sense, and has been previously demonstrated, that companies belonging to industries identified as socially irresponsible (e.g., known for polluting and engaging in other irresponsible activities) would tend to work toward improving their corporate image to separate themselves from the 'bad actors' in their respective industries. The differences between the tables relative to this variable subsequently suggests that the ENVIR variable may be too broad a construct to limit its explanatory value solely to the threat posed to the community due to pollution. Rather, it's likely a given industry will receive 
significant poor press from being an excessive polluter, which may also help to account for an increase in VPP companies in that industry. Indeed, this may be particularly so relative to multi VPP companies as strategy is undertaken at the corporate level to alter the image of the entire firm as opposed to individual establishments.

Table 4

Standardized Coefficients for Various Multiple Regression Equations for the Establishment Level Dependent Variable ESTAB

\begin{tabular}{lcccccc}
\hline $\begin{array}{l}\text { Establishment } \\
\text { Level }\end{array}$ & $\mathbf{1}$ & $\mathbf{2}$ & $\mathbf{3}$ & $\mathbf{4}$ & $\mathbf{5}$ & $\mathbf{6}$ \\
\hline LABOR & $.252^{*}$ & $.193^{*}$ & $.264^{* *}$ & & & \\
OSHA & $.330^{* *}$ & $.246^{*}$ & $.424^{* * *}$ & $.344^{* * *}$ & $.237^{*}$ & $.300^{* *}$ \\
ENVIR & & $.262^{*} .$. & $.179^{*}$ & $.108^{*}$ & $.210^{*}$ & \\
INJURAT & & & $-.567^{* * *}$ & $-.497^{* * *}$ & & \\
UNIO & & & & $.224^{* *}$ & $.306^{* *}$ & $.369^{* * *}$ \\
\hline $\mathbf{R}^{2}$ & .185 & .242 & .531 & .510 & .290 & .255 \\
ADJ. $\mathbf{R}^{2}$ & .166 & .216 & .509 & .487 & .266 & .238 \\
\hline
\end{tabular}

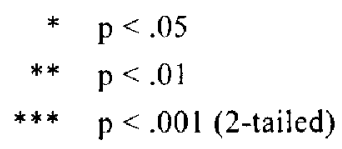

Table 4 depicts standardized coefficients for 6 multiple regression equations. The variables included in each equation are determined by the vertical equations. All regression equations were significant at $p<.001 . R^{\prime}$ values are also provided.

Aside from these differences, the trends identified in the two tables were essentially identical and were to be expected given a high degree of correlation noted in Pearson's correlations between the two dependent variables $(r=0.96, p<.001)$. Thus, regression analyses for both dependent variables describe a set of relationships where stakeholder power constructs, combined with the INJURAT variable, help to explain a great deal of variation in the dependent variables.

\section{Discussion and Conclusion}

\section{Discussion}

One of the most interesting aspects of the findings of this investigation is that all the hypotheses examined were confirmed by correlation analysis save for the INJURAT variable. This suggests value in the combined use of RDT 
and institutional theory for explaining and predicting the prevalence of beyond compliance safety and health programs within a given institutional field. That is to say, organizations faced with powerful, primary stakeholders that have the potential of withholding or otherwise controlling resources flowing through the firm are compelled to consider strategy designed to preempt such action. This study demonstrates the existence of direct relationships between the prevalence of a given strategy likely adopted to appease certain stakeholder groups and the relative power inherent in those groups.

Organizations, of course, need not invest resources to recreate the wheel in developing strategy to address potential concerns of important stakeholder groups, particularly when strategies have been successfully implemented elsewhere within the same or in a similar institutional field. Rather, it is more likely organizations will scan the external environment to identify strategies proven successful in a given institutional field in order to match strategy with the institutional environment (Elenkov, 1997). Hence, mechanisms such as mimesis, coercion, and normative isomorphic paths described by DiMaggio and Powell (1983) may be helpful in describing or predicting the prevalence of a given strategy within a given field. However, the firm's need for considering a given strategy will be more likely tied to survival and organizational success - via the unhindered flow of resources - than adoption for the sake of conformance within the field.

This perspective is consistent with Oliver's (1991) combined theory model. Strategy grows from active choice behavior rooted in active agency with the success of the organization in mind. Conformance for the sake of conformance in a quest for social legitimacy is insufficient for describing why firms elect to undertake resource intensive beyond compliance initiatives such as participation in VPP.

Also important to the findings of this investigation are the strong relationships noted between the negative public attention variables and VPP industry prevalence. This finding adds credence to assertions that mimesis is likely to occur in response to uncertainty generated by activism (DiMaggio and Powell, 1983; Shepard et al., 1997), and that socially responsible programs are likely to occur in tarnished industries as companies seek to set themselves apart from the crowd as exemplars of responsible management (Shepard et al., 1997; King et al., 2002). Examining the question of uncertainty, however, raises the question 'Uncertain of what?' And this uncertainty can be ultimately tied to survival and success. What does it matter that a company is accused of malfeasance if there are no repercussions relative to the flow of resources through the firm as a result of powerful stakeholders - such as customers, stockholders, and employees - choosing to exercise that power? Thus, strategies such as VPP participation are ultimately chosen out of consideration for powerful stakeholders, though they may be adopted via mechanisms best described by institutional theory.

Finally, some discussion is warranted of the INJURAT variable given the significant role played by this variable in the regression results. Recall that although the primary stakeholder influence variables utilized in the regression equa- 
tions made significant contributions to the overall equation, the addition of the INJURAT variable predicted a great deal of variation in the dependent variable, and also impacted other relationships in the equation. The role of this variable suggests that VPP participation is more prevalent in safer industries. And given the very limited impact the current low prevalence of VPP participation would have in driving industry rates (Corcoran, 2003), it is likely the perceived costs within high rate industries necessary to meet VPP participation standards may preclude VPP as the most cost effective means of gaining stakeholder support. Thus, the meat packing industry consisting of plants that employ thousands, experience high turnover, and require thousands of strenuous job tasks preformed by employees working shoulder to shoulder wielding razor sharp knives may be less inclined to consider VPP in their mix of socially responsible programs than the pharmaceutical industry that requires sophisticated control systems already be in place regardless of VPP participation.

\section{Conclusion}

The present study suggests value in a combined theoretical approach for explaining and predicting the prevalence of programs akin to VPP within a given industry. Tests utilizing resource dependence based variables, for instance, suggest that stakeholder resource control power influences organizational decision making. Companies tend to engage in programs that will reflect them in a positive light in the eyes of more powerful stakeholders. Likewise, companies will tend to adopt programs utilized by other organizations within their industries that are believed to be effective in reflecting them in such a light. Thus, the tests conducted in the present study suggest that the theoretical approaches of RDT and IT compliment one another in helping to explain the proliferation of programs like VPP within industries.

One difficulty inherent in the study, however, is the cross sectional nature of its design. This limitation imposed by the data available at the time the study commenced warrants caution when considering the cause and effect relationships supposed in this study. The inability to consider the impact of time and sequence on the relationships between independent and dependent variables limits, to a degree, the inferential value of the tests presented in this paper and makes it difficult to discern the relative impact of the three primary mechanisms leading to isomorphism proposed by DiMaggio and Powell (1983). We are limited, rather, to observing the sum impact of these mechanisms at work. Regardless, the crosssectional correlations found in this paper do provide positive evidence of causality, though longitudinal data would provide stronger evidence and would help to establish the relative impact of coercive, mimetic, and normative isomorphic mechanisms in relation to VPP proliferation within industries.

Finally, these limitations do not entirely emasculate the findings of this work. The fundamental theoretical arguments undergirding this research, rather, tend to be supported by the findings. In addition, important relationships of practical significance were disclosed providing a foundation for further thought and study. Indeed, 
the present study provides the strategic management practitioner some insight as to how socially responsible action might be utilized as a strategic tool in dealing with powerful stakeholders. Such disclosure provides more overt consideration of the strategic value of beyond compliance programs in the decision making process. In scanning the environment for opportunity and strategic advantage, responsible action now looms as a potential stratagem for gaining stakeholder support due to this and many other studies designed to uncover how and why firms choose the socially responsible path to management. Considering these strategic implications in terms of stakeholder resource control power and contemplating likely mechanisms by which industries respond to this power can only help strategic managers in making more conscious, well informed strategic decisions

\section{References}

Abernethy, M. A., \& Fong, C. W. (1996). A field study of control system "redesign": The impact of institutional processes on strategic choice. Contemporary Accounting Research, 13, 569-603.

Besser, T. L. (1999). Community involvement and the perception of success among small business operators in small towns. Journal of Small Business Management 37, 16 80 .

BLS, Bureau of Labor Statistics. (2002). Industry injury and illness data. Retrieved August 1, 2003 from www.bls.gov/iif/oshsum.htm.

Corcoran, D. J. (2003). The applicability of resource dependence theory and institutional theory to voluntary, beyond compliance occupational health and safety programs. Doctoral dissertation, Touro University International.

DiMaggio, P., \& Powell, W. (1983). The iron cage revisited: Institutional isomorphism and collective rationality in organizational fields. American Sociological Review, 48 , 147-160.

Elenkov, D. S. (1997). Strategic uncertainty and environmental scanning: The case for institutional influences on scanning behavior. Strategic Management Journal, 18, 287-305.

Frooman, J. (1999). Stakeholder influence strategies. The Academy of Management Review, 24, 191-205.

Jawahar, J. M., \& McLaughlin, G. L. (2001). Toward a descriptive stakeholder theory: An organizational life cycle approach. Academy of Management Review, 26, 397-414.

King, A., Lenox, M., \& Barnett, M. (2002). Strategic responses to the reputation commons problem. In A. J. Hoffman \& M. J. Ventresca (Eds.), Organizations, policy, and the natural environment (pp. 393-406). Palo Alto, CA: Stanford University Press. 
Levine, S.P., \& Dyjacka, D. T. (1997). Critical features of an auditable management system for an ISO 9000-compatible Occupational Health and Safety Standard. American Industrial Hygiene Association Journal, 5, 291-298.

Lucas, J. A., Avi-itzhak, T., Robinson, J. P., \& Morris, C. G. (2005). Continuous quality improvement as an innovation: Which nursing facilities adopt it? Gerontologist, 45, 68-78.

Manuele, F. (2003). On the practice of safety ( $3 \mathrm{rd}$ ed.). Hoboken, NJ: John Wiley \& Sons, 369-389.

Mills, D. (1994). Labor-Management Relations (5th ed.). New York: McGraw-Hill.

Milstein, M. B., Hart, S. L., \& York, A. S. (2002). Coercion breeds variation: The differential impact of isomprphic pressures on environmental strategies. In A. J. Hoffman \& M. J. Ventresca (Eds.), Organizations, policy, and the natural environment (pp. 151-172). Palo Alto, CA: Stanford University Press.

OSHA(a). Voluntary protection programs: An OSHA voluntary program. Retrieved May 13, 2005, from www.osha.gov/dcsp/vpp/index.html.

OSHA(b). Industries in the VPP federal and state plans as of 3/31/2005. Retrieved May 13, 2005, from www.osha.gov/desp/vpp/sitebysic.html.

OSHA(c). Frequently cited OSHA standards. Retrieved March 11, 2003, from www.osha. gov/pls/imis/citedstandard.html.

Oliver, C. (1991). Strategic responses to institutional processes. Academy of Management Review, 16, 145-179.

Peng, M. W. (2004). Outside directors and firm performance during institutional transitions. Strategic Management Journal, 25, 453-471.

Pfeffer \& Salancik. (1978). The external control of organizations: A resource dependence perspective. New York: Harper and Row.

Prakash, A. (2001). Why do firms adopt 'beyond-compliance' environmental policies? Business strategy and the environment, 10, 286-299.

Prakash, A. (2000). Greening the firm: The politics of corporate environmentalism. New York: Cambridge University Press.

Scott, R. W. (1995). Institutions and Organizations. Thousand Oaks, CA: Sage.

Shepard, J. M., Betz, M., \& O'Connell, L. (1997). The proactive corporation: Its nature and causes. Journal of Business Ethics, 16, 1001-1010. 
Skrzycki, C. (2005, August 30). Agency alliances with industry growing. The Washington Post, p. DI.

Tsai, S. H., \& Child, J. (1997). Strategic responses of multinational corporations to environmental demands. Journal of General Management, 23, 1-23.

U.S. Census Bureau. Number of firms, number of establishments, employment, annual payroll, and receipts by employment size of the enterprise for the United States, all industries - 1997. Retreived July, 15, 2003, from www.census.gov/csd/susb/usalli97.xls.

U.S. Census Bureau. State and county quick facts. Data retrieved July, 1993, by searching for county population by VPP site zip code at quickfacts.census.gov/cgi-bin/lookup.

U.S. EPA. TriExplorer. TRI Values retrieved on July 18, 2003, from www.epa.gov/triexplorer/facility.htm.

Daniel J. Corcoran is the Assistant Area Director of the Kansas City Area OSHA office and is an Assistant Professor of Business Administration at Touro University International. He received his Ph.D. from Touro University International in Business Administration and a Master of Public Administration degree at the University of Nebraska at Omaha, where he also received his B.S. in biology.

Joshua D. Shackman is an Associate Professor of Business Administration and Health Sciences at Touro University International. He received his Ph.D. from the University of California, Los Angeles in economics, and his B.A. in economics from the University of Michigan. 